\title{
Design and Implementation of A Contemporary Health Administration Program For Health Managers
}

Hanan Khalil ( $\nabla$ h.khalil@latrobe.edu.au )

La Trobe University https://orcid.org/0000-0002-3302-2009

Chaojie Liu

La Trobe University - Bundoora Campus: La Trobe University

\section{Research}

Keywords: Master of Health Administration, Pedagogy, Management Competency

Posted Date: July 14th, 2021

DOI: https://doi.org/10.21203/rs.3.rs-666772/v1

License: (c) (i) This work is licensed under a Creative Commons Attribution 4.0 International License.

Read Full License 


\section{Abstract}

\section{Background}

While there are core competencies required in health administration programs, little has been known about how they are taught in health administration programs to support/change practices. This discussion paper describes an educational innovation to design a contemporary Master of Health Administration program to meet the current needs of health managers in Australia based on evidencebased practice.

\section{Method}

A detailed gap analysis of health managers educational needs was undertaken with various stakeholders to design a contemporary health managers' program. Stakeholders surveyed in the course design included prospective students, international students' agencies, prospective employers, Alumni evaluation, mapping of health managers courses in Australia and faculty feedback. An integrative pedagogical approach was used to implement the program into action.

\section{Results}

Various themes were emerged from the stakeholder consultations including the importance of basic knowledge of key subjects and the significance of learning new skills such as strategic planning and emotional intelligence in the workplace. The integrative pedagogical approach used is based on adult teaching principles, which were identified by Knowles. The subjects in the new course incorporate several knowledge-based presentations along with interactive activities, including use of general ability-based outcomes to define learning opportunities, case-based and problem-based learning, experiential learning, and comprehensive assessments.

\section{Conclusion}

The results of this intensive consultation led to the design of a contemporary Master of Health Administration Course that included eight core subjects and multiple options of specialisations for students to choose from. Examples of specialisations include aged care and ageing, health promotion, data for decision making, public health, international development and Health Strategy and decision making.

\section{Background}

Healthcare management programs play an essential role in preparing future managers in health services to deliver appropriate and efficient care in health services $(1,2)$. Although there are undergraduate degree courses in health administration programs, it has been widely recognised that postgraduate training is more adequate to prepare health management workforce. Most postgraduate training courses offer students practical skills on top of their existing foundation knowledge $(3,4)$. However, great variations 
exist in contents and delivery of these courses. Arguably, this is a response to the diverse backgrounds and needs of health managers. A study by Bonica et al., 2018 has used an open pedagogy to develop competency for health care programs (5). The authors argued that having open access resources available for students led them enhancing their soft skills and management. This methodology was complemented with assignments and discussion of outcomes. This teaching method relied on selfdirection with the use and creation of open educational resources. The authors added that this method is well suited for health mangers as they are expected to be self-directing and have exploratory nature which appear to be effective for exercising the softer competencies, such as achievement orientation, information seeking, team leadership, and organizational awareness (5).

Despite the diverse background of health managers, empirical evidence shows that a set of essential management skills are required to enable achievement of high performance of a health organisation in relation to the organisation and its employees, consumers and other external stakeholders $(6,7)$. Health management professional bodies in some countries have started to develop a unified management competency framework $(4,8)$. Most of the competencies endorsed by these associations include components of leadership, knowledge of health and health care environment, business skills, communication and management skills and professional responsibilities $(9,10)$. These may also include social responsibilities from a population health perspective, addressing issues like cultural diversity and health disparity (11-13).

Over the years, most health administration training programs have evolved to address several competencies highlighted by the various professional associations of health managers $(4,10)$. To date, however, only a few published programmes have cited a basis of a pedogeological framework for their program. A study published by Abad Jorge et al., 2017 described pedagogical approaches for integrating cultural competency in a healthcare management program. The authors used this framework to address the health disparities amongst culturally diverse populations (8). The program included educational content on cultural competency, understanding and managing diversity, and the benefits of diversity leadership in healthcare. The authors used a variety of methods of teaching to cater for the various types of learners (8). More recently, a paper published by Caron et al., 2018 highlighted the use of population health pedagogy to address the evolving changes in health care challenges (14). The use of population health pedagogy includes the use of real data to assess the health requirements of a particular community; analyse and interpret diverse data sets; develop practical solutions to complex health issues based on evaluation and finally, successfully communicate to wide-ranging stakeholders.

A student-centred participatory approach is critical for students to obtain competencies required for health administration $(8,15)$. A recent integrative review reported various innovative pedagogical practices used in higher education aiming to increase students' engagement, motivation and critical thinking. Several approaches to increase reflection, higher level thinking, and deep learning are all essentials for students' learnings (16). Collaborative learning strategies where students learn from their peers and faculty are also encouraged as they resulted in higher engagement and conceptual understanding $(17,18)$. This is in addition to the use of various digital simulation tools ranging from 
videos to explain concepts, feedback provision and exist surveys to evaluate teaching $(19,20)$. The use of flipped classrooms was also encouraged in large classes due to its benefits in managing large numbers $(21,22)$. Having students access materials beforehand enabled them to come back with some ideas to discuss concepts with their peers and learn from each other through case studies and experiences from each other.

This paper describes the development of a contemporary Master of Health Administration (MHA) program in Australia involving an integrative pedagogical approach to implement the program into action. It is important to note that many of the health administration programs are still evolving and their curricula are constantly being updated to keep up with the evolving nature of health care and the challenging issues health managers face. Examples of these issues include the recent COVID 19 pandemic, rising costs of care and demands from consumers to deliver quality care in health services.

\section{Method}

Re-design of an existing MHA course was conducted in 2020 through extensive stakeholder consultations. Both the existing and the revised courses went through accreditations from the Australasian College of Health Service Management in line with its management competency framework.

\section{Gap analysis and contents design}

A detailed gap analysis of health managers educational needs was undertaken with various stakeholders. The GAP analysis methodology is a relatively widely used approach for quality assurance processes in organizations that deliver services (23). However, it has been used only seldom in the university sector and the most frequent problems of its implementation include its difficult interpretation (24). Figure 1 shows the various stakeholders consulted in the gap analysis to generate the requirement for a contemporary health administration program. The Gap analysis consisted of a four-step approach; firstly, we identified the current state of the course by consulting with Master of Health Administration (MHA) Alumni who completed the course from 2012 until 2019. We have undertaken this step for both the local and the international program run by the University. Ethics approval was obtained for the Alumni evaluation section of the project. Secondly, in order to identify where we wanted to be and what the new course design should entail, we have subcontracted market research undertaken by an independent consulting firm to engage potential employers, students and international agencies in a discussion about the future needs of health services managers in the workplace, including their opinions about the skills and knowledge required for them to engage in this evolving industry. Thirdly, we have identified the gaps in the current course through mapping the existing course against a set of competencies and similar courses offered in other Australian universities wherever their curriculum was made publicly available. The set of competencies were chosen based on the Royal Australian College of Medical Administrators (RACMA) framework, the Australasian College of Health Services Management (ACHSM) and the commission on Accreditation of Health Management Education (CAHM). These include: knowledge of 
health systems, systems improvement, finance, health policy, epidemiology, leadership, capstone/research project and work integrated learning. Student and external stakeholder expectations were summarised and discussed in our internal teaching and learning workshops. Finally, we have devised a plan for improvements of the current course in line with the adult teaching principles identified by Knowles. This was undertaken with the consultation of current students and faculty staff.

\section{Implementation plan of the newly designed course}

An integrative pedagogical approach was used to plan implementation of the program. This approach has been successfully used in the transition to online delivery of the MHA course. Figure 2 details the basic concepts of the approach undertaken. It is consistent with adult learning principles as mentioned by Knowles et al, emphasizing use of general ability-based outcomes to define learning opportunities, case-based and problem-based learning, experiential learning and comprehensive assessments. Several strategies were employed to deliver this design, these included the extensive use of digital technologies for promoting engagement and motivation as seen in many courses, clear and succinct instructions to guide the learner to navigate the course content. This was also supported by aligning the outcomes of each subject with all the course outcomes as well as the topics delivered in each week and ensuring the assessments are relevant to the content delivered. Ensuring a culture of support and online presence by the faculty staff was also necessary to ensure guidance and appropriate and timely feedback. Finally, the use of real-life case studies and data to engage the learners and ensure the applicability of the content to the workplace was introduced in all assessments.

\section{Results}

The results of the gap analysis are detailed below for each section of the gap analysis

\section{MHA alumni evaluation}

The findings of the MHA evaluation have been described in full elsewhere. Briefly, the Alumni valued knowledge of project management, health services resources management, program evaluation and human resources as essential to their workplace. Skills addressing emotional strategic thinking and planning, resilience and emotional intelligence were also rated highly by all Alumni to be essential for the workplace. More than $90 \%$ of All Alumni secured a promotion within their own organisation or ended up being seconded to another organisation in a higher role. Furthermore, Alumni valued the flexible mode of delivery of the course to be essential as most of them were working in a full-time capacity and were only available to study part time due to their work and personal commitments. Recommendations to improve the course included having guest lectures from the industry and incorporated work placements as future suggestions to improve the course.

\section{Mapping of MHA courses}


A total of ten Health Administration courses taught in Australian Universities were identified and their core contents were mapped against the common areas identified by RACMA, ACHSM and CAHM. Each subject within each university curriculum was allocated one unit against the relevant theme it falls under. Most Australian Health Administration courses had subjects in the themes identified by the accreditation bodies.

Core subjects addressing systems improvement consisted of $26 \%$ of the contents. Examples of these subjects include: program development and evaluation, evidence informed decision and using health care data for decision making. Management/leadership and knowledge of the health system each represented about $19 \%$ of the curriculum. Examples of subjects that align with these themes were health leadership and workforce management and the Australian health system respectively. Furthermore, most Universities had a choice of either a capstone projector or a research project. Only one university in Australia offered a placement for 12 weeks. Figure 3 shows the breakdown of topics within each theme by university.

\section{Market research}

One of the challenges in the re-design of the MHA course is to meet the diverse needs of students. In Australia a MHA course is usually taught through 1.5 (for students with a cognate degree in health) or 2 years (for students without a cognate degree in health). We proposed seven streams of specialisations (e.g. Applied Research, Health Promotion, Health Policy, Health Administration, Community Engagement, Ageing in Society, and Ergonomics, Safety and Health) to meet the diverse need. The main objectives of the marketing brief were to understand the value of specialisations in increasing employment prospects and/or career development, to understand overall appeal, industry alignment and impact on employment prospects of and to identify gaps in our specialisations' offer that would increase chances of employment of prospective students and to identify trends and industry skills future demand. The target groups for the market research included a total of ten participants consisting of employers in the health administration area, the university's Alumni, international agents recruiting students for the Master of Health Administration and prospective students. The results from the marketing confirmed the importance of specialisations that were seen as an important differentiator away from a 'generic' masters' degree. The results also highlighted the importance of providing information regarding why students choose one speciality over another and the differences between them. The findings from market research highlighted that there are three threads to potential specialisations including the following:

- Specialisations that push the MHA in particular into bigger picture spaces with a greater emphasis on strategic thinking within the health system

- Specialisations that could form part of any of the Masters' degrees that reflect the likely long terms changes as a result of Covid-19

- Specialisations that suit niche interests or very specific future careers.

\section{Current students and staff consultation}


A consultation of current students and staff took place separately before finalising the content of the new course to seek their opinions about the content and the mode of delivery of the course. Both groups endorsed the overall structure of the re-designed course but highlighted the importance of maintaining the flexible delivery of the course and the need to update the course content and the resources provided to the students. In line with the demands, the development of subjects embedded in this course looked at previous feedback of subjects taught over the years. The subjects that were rated poorly by students were identified to be needed a significant amendment of course content, assessment, and delivery.

\section{Accrediting of the MHA program}

The re-designed MHA course went through the accreditation from the Australian College of Australasian College of health services managers, which not only required a comprehensive coverage of all its core competencies, but also an assurance of effective arrangements of teaching delivery. This was the stage where further refinements of the subjects' content took place to ensure it is aligned with requirements of accreditation. The re-designed MHA course contains eight core subjects: PHE5HHS -Health Systems; PHE5SOM - Strategy and operation management; PHE5FMH - Financial Management in Health Services; PHE5MLH- Management and leadership in Health; PHE5HCQ -Health Care Quality; PHE5EPB Epidemiology and Biostatistics; PHE5LAE- Health law and Ethics; and PHE5STL-System thinking and Leadership. These core subjects have covered all required core competencies including leadership, knowledge of health and healthcare environment, business skills, communications and relationships management and professional and social responsibilities as shown in Figure 4.

\section{Discussion}

The design and implementation of the new MHA course relied on best practice that included multiple stakeholders' consultation and evaluations from past students who are currently in practice. To our knowledge, this is the first course in Australia that was based on a gap analysis including engagement of multiple stakeholders, a robust pedagogy and the inclusion of several contemporary teaching pedagogy that relied on a solid blueprint of the course learning outcomes to align with the subjects intended learning outcomes and the assessments that included many real cases studies that promotes engagement from the learners and sharing case studies from their workplace.

The introduction of the specialisations has been a major change in the course and has been welcomed by employers and prospective students as it was highlighted to be needed by potential employers due the ongoing challenges that the health system is facing due to the pandemic, increasing costs of health care and shortages of trained workforce in the health sector that are suited for the upcoming challenges and the increased expected demands of health managers projects by the Australian Health Workforce agency $(25,26)$.

The specialisation arrangements can also be better tailored to the diverse needs of students arising from different professional and cultural backgrounds. Student profiles in the MHA course often mimic the diversity in workforce in the health industry. Management position descriptions can also vary significantly 
across different levels and different disciplines. One of the major changes in subject development in the re-designed course is to extend the focus on the Australian health system to international health systems. This will not only be attractive to the international students but also to the domestic students. It is important to recognise that countries can learn from each other.

The successful design and implementation of the course was undertaken using the triple $\mathrm{C}$ model, where a focus on consultation, collaboration and consolidation was employed $(27,28)$. The model was previously used to address complex organisations in health services $(29,30)$. However, it was found to be useful in implementing the course design and delivery. This step of the process relied on having a collaborative teaching team who had the knowledge and expertise in subject development and being innovative about how to align assessments and content with the learning outcomes of each subject and the course as a whole.

Future work will focus on evaluation of this course to meet the changing demands of the sector and the usefulness of the list of specialisations introduced into the new course. Identifying the most popular specialisations offered will provide an insight into the industry demands and the support that future managers are needing to address their work challenges.

\section{Declarations}

\section{Ethics approval}

Ethics approval was obtained for the Alumni evaluation section of the project (.

\section{Consent for publication}

Both authors ( $\mathrm{HK}$ and $\mathrm{CL})$ consent to the publication of the manuscript.

\section{Competing interests}

The authors declare no competing interests

\section{Funding}

There was no funding support for this publication

\section{Authors Contributions}

HK designed and drafted the manuscript. CL has commented on it and provided input and feedback on the final copy.

\section{Acknowledgments}

The authors would like to thank the participants involved in all stages of the course development, including staff and students at the university. 


\section{References}

1. Cellucci LW, Molinari C, Young J. Competency-based education in undergraduate programs certified by the association of university programs in health administration. The Journal of Health Administration Education. 2018;35(2):175.

2. Galipeau J, Moher D, Campbell C, Hendry P, Cameron DW, Palepu A, et al. A systematic review highlights a knowledge gap regarding the effectiveness of health-related training programs in journalology. Journal of Clinical Epidemiology. 2015;68(3):257-65.

3. Porter JA, Haberling K, Hohman C. Employer desired competencies for undergraduate health administration graduates entering the job market. The Journal of Health Administration Education. 2016;33(3):355.

4. Sonnino RE. Health care leadership development and training: progress and pitfalls. Journal of Healthcare Leadership. 2016;8:19.

5. Bonica MJ, Judge R, Bernard C, Murphy S. Open pedagogy benefits to competency development: From sage on the stage to guy in the audience. The Journal of Health Administration Education. 2018;35(1):9.

6. Bradley EH, Taylor LA, Cuellar CJ. Management matters: a leverage point for health systems strengthening in global health. International journal of health policy and management. 2015;4(7):411.

7. Bruno A, Bates I. Transforming our Workforce: workforce development and Education systems, tools and navigation. 2016.

8. Abad-Jorge AR, Kronenburg MA, Biggs RN. Pedagogical strategies for integrating cultural competency in a healthcare management program. The Journal of Health Administration Education. 2017;34(4):585.

9. Baker SL, Beitsch L, Landrum LB, Head R. The role of performance management and quality improvement in a national voluntary public health accreditation system. Journal of Public Health Management and Practice. 2007;13(4):427-9.

10. West DJ, Ramirez B, Filerman G, Stanowski A, Vasadze O, Malik AM, et al. Global Accreditation Strategies in Health Management Education. Frontiers in public health. 2019;7:12.

11. Aaronson W, West D, Heshmat S, Ramirez B. The pillars of health management education: lessons from the CEE experience. The Journal of health administration education. 1998;16(2):125-44.

12. Reich $M$, Czeglédi $C$, Fonger J. Expectations of Employees on the Effects of the Workplace Health Management as a Part of an internal Diversity Management-an explorative study. 2015.

13. Lichtenstein R. Promoting diversity in health management: The University of Michigan experience. Journal of Health Administration Education. 2005;22(3):251.

14. Caron RM, Hooker EA, Hewitt AM, Carmalt JH. Pedagogy: How to best teach population health to future healthcare leaders. Journal of Health Administration Education. 2018. 
15. Levy R, Dickerson C, Teague J. Developing blended learning resources and strategies to support academic reading: a student-centred approach. Journal of further and higher education. 2011;35(1):89-106.

16. Santos J, Figueiredo AS, Vieira M. Innovative pedagogical practices in higher education: An integrative literature review. Nurse Education Today. 2019;72:12-7.

17. Rutherford SM. Collaborative learning: Theory, strategies and educational benefits: Nova; 2014.

18. Hmelo-Silver CE, Chinn CA. Collaborative learning. Handbook of educational psychology: Routledge; 2015. p. 363-77.

19. Akbar M. Digital technology shaping teaching practices in higher education. Frontiers in ICT. 2016;3:1.

20. Khanduja PK, Bould MD, Naik VN, Hladkowicz E, Boet S. The role of simulation in continuing medical education for acute care physicians: a systematic review. Critical care medicine. 2015;43(1):186-93.

21. O'Flaherty J, Phillips $C$. The use of flipped classrooms in higher education: A scoping review. The internet and higher education. 2015;25:85-95.

22. McLean S, Attardi SM, Faden L, Goldszmidt M. Flipped classrooms and student learning: not just surface gains. Advances in physiology education. 2016.

23. Franklin M. Performance gap analysis: Tips, tools, and intelligence for trainers: American Society for Training and Development; 2006.

24. Bernhard A. Quality assurance in an international higher education area: Springer; 2011.

25. Khalil H, Liang Z, Karimi L, Ferrier JA, Leggat SG. Guidance to implementing evidence-based initiatives to manage pandemics in healthcare services: a discussion paper. JBI Evidence Implementation. 2020;18(4):401-7.

26. Figueroa CA, Harrison R, Chauhan A, Meyer L. Priorities and challenges for health leadership and workforce management globally: a rapid review. BMC health services research. 2019;19(1):1-11.

27. Khalil H, Kynoch K. Implementation of sustainable complex interventions in health care services: the triple C model. BMC Health Services Research. 2021;21(1):1-10.

28. Khalil $\mathrm{H}$. The triple $\mathrm{C}$ (consultation, collaboration and consolidation) model: a way forward to sustainability of evidence into practice. LWW; 2017.

29. Khalil H. Successful implementation of a medication safety program for Aboriginal Health Practitioners in rural Australia. Australian Journal of Rural Health. 2019;27(2):158-63.

30. Khalil H, Byrne A, Ristevski E. The development and implementation of a clinical skills matrix to plan and monitor palliative care nurses' skills. Collegian. 2019;26(6):634-9.

\section{Figures}




\begin{tabular}{l} 
MHA Alumni \\
evaluation \\
$\begin{array}{c}\text { Alumni (Local } \\
\text { Program) 2012- } \\
2019\end{array}$ \\
$\begin{array}{c}\text { Alumni 2017- } \\
2019 \\
\text { (International } \\
\text { Program ) }\end{array}$ \\
\hline
\end{tabular}

Mapping of all courses

Market research

A total of 10

MHA courses

were mapped

against set

Competency

criteria
Students and staff consultation

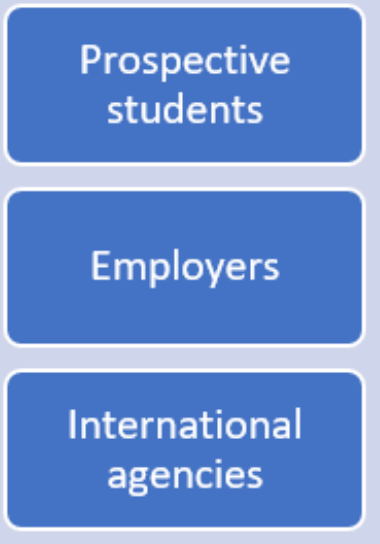

2020 MHA students

Staff

\section{Figure 1}

Details of the stakeholders involved in the Gap analysis

Mapping subject learning outcomes with course intended learning outcomes

Alignment of course objevtives with subjects learning outcomes, contents and assessments

The use of digital technology

Guided instructions with personalized learning

Culture of support and timely feedback

Introduction of real life case studies

\section{Figure 2}

Strategies used to implement the newly designed course 


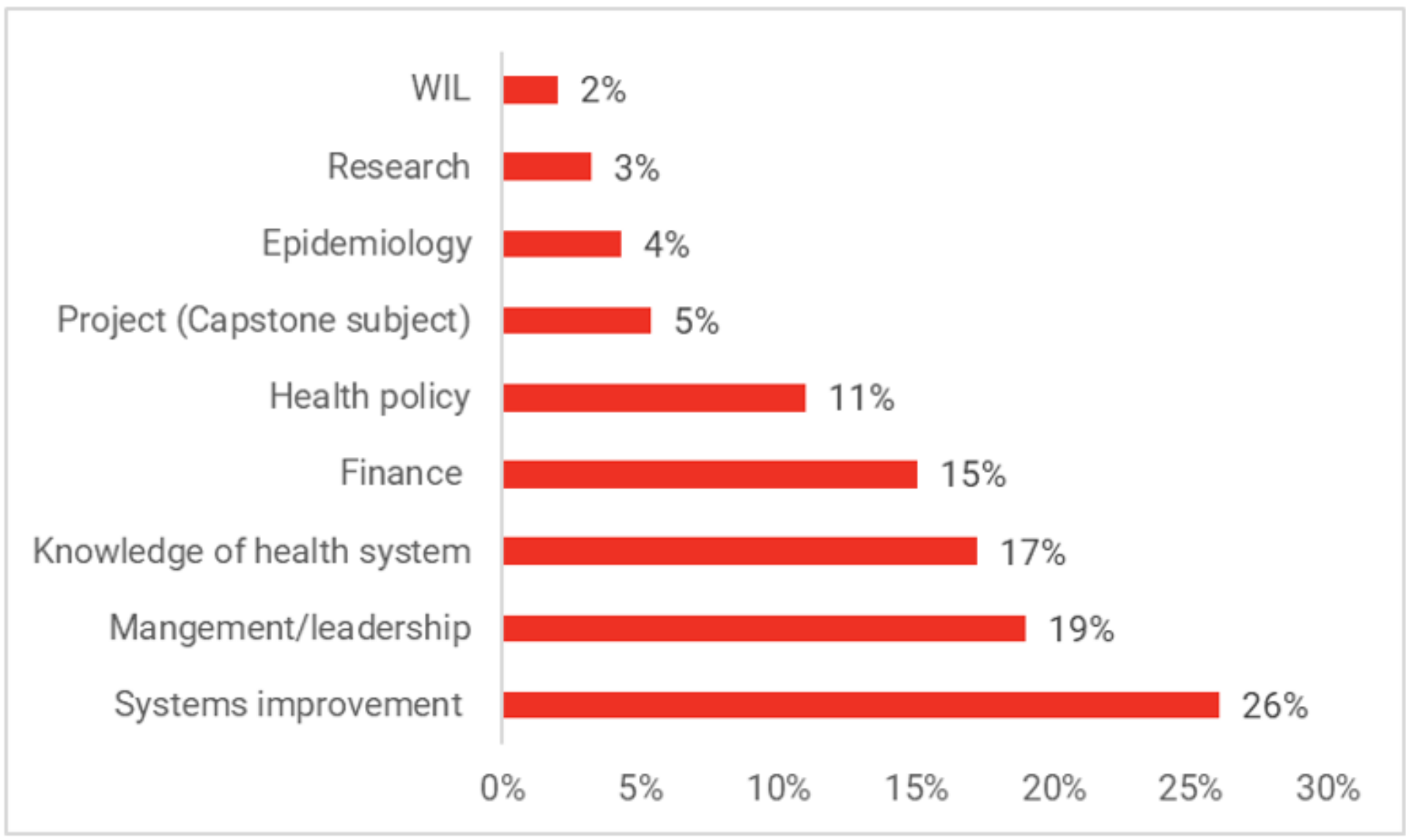

\section{Figure 3}

Proportion of themes in Australian Content of MHA courses 


\begin{tabular}{|c|c|c|c|c|c|c|c|c|c|}
\hline \multirow[b]{2}{*}{ 1. LEADERSHIP } & \multirow[b]{2}{*}{ 1.1 Leadership Skills and Behaviours } & \multicolumn{8}{|c|}{ Core subjects } \\
\hline & & MLH & PMH/ALS & SOM & 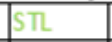 & & & & \\
\hline & 1.2 Influences Organisational Climate & MLH & $\mathrm{HCQ}$ & SOM & LAE & STL & & & \\
\hline & 1.3 Leading Change & MLH & PMH/ALS & $\mathrm{HCQ}$ & SOM & STL & & & \\
\hline $\begin{array}{l}\text { 2. HEALTH AND } \\
\text { HEALTHCARE } \\
\text { ENVIRONMENT }\end{array}$ & 2.1. Health Systems and Organisations & FMH & HHS & PMH & SOM & LAE & STL & & \\
\hline & 2.2 Health workforce & MLH & FMH & HHS & $\mathrm{PMH}$ & LAE & & & \\
\hline & $\begin{array}{l}\text { 2.3 Partnering with organisations ion to Health Promotion } \\
\text { action }\end{array}$ & MLH & PMH/ALS & Som & & & & & \\
\hline & 2.4 Population Health & MLH & HHS & EPB & $5 T 2$ & & & & \\
\hline 3. BUSINESS SKIUS & 3.1 Evidence Informed Decision-Making & MLH & FMH & EPB & PMH & ALS/THA & STL & SOM & $\mathrm{QRM} / \mathrm{QM}$ \\
\hline & 3.2 Financial and Resource Management & FMH & HHS & $\mathrm{PMH}$ & SOM & & & & \\
\hline & 3.3 Human Resource Management & MLH & $\mathrm{PMH}$ & SOM & & & & & \\
\hline & 3.4 Organisational Dynamics And Governance & MLH & HHS & SOM & LAE & STL & & & \\
\hline & 3.5 Planning and Marketing & MLH & $\mathrm{PMH}$ & $\mathrm{SOM}$ & & & & & \\
\hline & 3.6 Information Management & EPB & PMH & ALS/THA & QRM/Q & & & & \\
\hline & 3.7 Risk Management and Clinical Governance & MLH & PMH/ALS & SOM & \begin{tabular}{|l|l|l|} 
LAE \\
\end{tabular} & & & & \\
\hline & 3.8 Quality and Safety & MLH & EPB & PMH/ALS & $\mathrm{HCQ}$ & SOM & & & \\
\hline & 3.9 Project, Supply Chain and Facilities Management & MLH & FMH & PMH/ALS & SOM & & & & \\
\hline $\begin{array}{l}\text { 4. COMMUNICATIONS } \\
\text { AND RELATIONSHIP } \\
\text { MANAGEMENT } \\
\end{array}$ & 4.1 Relationship Management & MLH & PMH/ALS & STL & & & & & \\
\hline & 4.2 Communication Skills & MLH & PMH/ALS & PMH & SOM & & & & \\
\hline & 4.3 Conflict and Problem Management & MLH & PMH/ALS & som & STL. & & & & \\
\hline $\begin{array}{l}\text { 5. PROFESSIONALAND } \\
\text { SOCLAL RESPONSIBILTYY }\end{array}$ & 5.1 Professionalism & MLH & FMH & PMH & ALS/THA & STL & SOM & LAE & \\
\hline & 5.2 Profession and Professional Development & MLH & $\mathrm{HCQ}$ & & & & & & \\
\hline & 5.3 Self-Awareness & MLH & $\mathrm{PMH}$ & SOM & LAE & STL & & & \\
\hline & 5.4 Social Responsibility & MLH & HHS & som & LAE & STL & 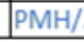 & & \\
\hline
\end{tabular}

\section{Figure 4}

Mapping of subjects against core competencies of the accrediting organisation PHE5HHS -Health Systems; PHE5SOM - Strategy and operation management; PHE5FMH - Financial Management in Health Services; PHE5MLH- Management and leadership in Health; PHE5HCQ -Health Care Quality; PHE5EPB - Epidemiology and Biostatistics; PHE5LAE- Health law and Ethics; and PHE5STL- System thinking and Leadership; ALS-Action learning studies) 